\title{
Desorption Electrospray Ionization (DESI) Mass Spectrometry and Tandem Mass Spectrometry (MS/MS) of Phospholipids and Sphingolipids: Ionization, Adduct Formation, and Fragmentation
}

\author{
Nicholas E. Manicke, Justin M. Wiseman, Demian R. Ifa, \\ and R. Graham Cooks \\ Department of Chemistry, Purdue University, West Lafayette, Indiana, USA
}

Desorption electrospray ionization (DESI) mass spectrometry was evaluated for the characterization of glycerophospholipid standards, including glycerophosphocholine (GPCho), glycerophosphoglycerol (GPGro), glycerophosphoethanolamine (GPEtn), glycerophosphoserine (GPSer), glycerophosphoinositol (GPIns), cardiolipin (CL), and sphingolipid standards, including sulfatides (ST) and sphingomyelin (SM). Of specific interest were the effects of surface and solvent composition on signal stability and intensity, along with the ions observed in the full scan mode and the fragmentations seen upon collisional activation for each of the above classes. These experiments were performed without the addition of matrix compounds to the sample and were conducted in the free ambient environment at atmospheric pressure. The compounds GPSer, GPGro, GPIns, ST, and CL were best analyzed in the negative ion mode while PE was ionized efficiently in both positive and negative ion modes. SM and GPCho, which typically generate more abundant ions in the positive ion mode, could be analyzed in the negative ion mode by the addition of anionic reagents such as acetate to the spray solvent. Full scan DESI mass spectra and tandem (MS/MS) spectra for this representative set of physiological phospho/sphingolipids are presented. Similarities with other ionization methods in terms of fragmentation behavior were strong, although ambient ionization of untreated samples is only available with DESI. The effect of surface and solvent properties on signal intensity and stability were determined by depositing standard compounds on several different surfaces and analyzing with various proportions of methanol in the aqueous spray. Analysis was extended to complex mixtures of phospholipids and sphingolipids by examining the total lipid extract of porcine brain and by direct analysis of rat brain cryotome sections. These types of mixture analyses and molecular imaging studies are likely to represent major areas of application of DESI. (J Am Soc Mass Spectrom 2008, 19, 531-543) (c) 2008 American Society for Mass Spectrometry

$\mathrm{G}$ lycerophospholipids and sphingolipids are major constituents of biological membranes and have pivotal roles in a variety of biological processes including transmembrane signaling, localization of membrane proteins and cell-cell adhesion [1]. These molecules are distributed within tissues in the outer cell membrane and in intracellular compartments. Various molecular species occur in characteristic proportions in different species, organs, and organelles, and in different developmental stages and disease states. As such, lipids can serve as biomarkers of disease state. The composition of lipids in biological membranes also affects membrane fluidity, which can alter many important biological processes mediated by the

Address reprint requests to Dr. R. G. Cooks, Department of Chemistry, Purdue University, 560 Oval Drive, West Lafayette, IN 47907, USA. E-mail: cooks@purdue.edu activity of membrane-bound proteins. The identification, characterization, and quantitation of these compounds in biological systems is critical for the understanding of the underlying mechanisms of certain disease processes, examples of which include Alzheimer's and Niemann Pick diseases.

Mass spectrometric (MS) investigations of various classes of lipids have been performed utilizing a variety of ionization techniques, including chemical ionization (CI) [2-5], fast atom bombardment (FAB) [6-9], electrospray ionization (ESI) [10-17], secondary ion mass spectrometry (SIMS), and matrix-assisted laser desorption/ionization (MALDI) [18-27]. ESI and CI methods require that the sample, generally in the form of tissue or a cell culture in clinical work and biochemical experiments, be homogenized, and the phospholipids extracted in the course of liquid-liquid extraction and chromatographic steps. Preparation of 
the samples in this way is time-consuming and reagent intensive, and does not allow in situ analysis of intact biological tissues. More direct methods of tissue analysis are possible using MALDI, which nevertheless requires that the matrix first be applied to the sample and that it is then introduced into the high vacuum environment of the instrument, where it is inaccessible to further physical or chemical manipulation.

Desorption electrospray ionization (DESI) mass spectrometry was introduced as a new method for rapid surface analysis; DESI-MS does not require the addition of matrix compounds and is conducted at atmospheric pressure under ambient conditions. On the other hand, the lack of sample preparation means that ionization suppression and other effects are possible. In previous studies, DESI-MS was applied, for example, to the analysis of intact, untreated bacteria, where it allowed for the differentiation of subspecies largely based on phospholipid distribution [28]. Mammalian tissue has also been analyzed directly in the ambient environment by DESI-MS. Histological tissue sections from resected malignant human liver adenocarcinoma were analyzed without further preparation [29]. The results showed differences in the lipid profiles of the non-tumor region compared with the tumor region of the tissue. In particular, the intensities of certain sphingomyelin species marked the margin between the non-tumor and the tumor portion of the tissue sections. More recently, two-dimensional molecular ion images of thin sections of rat brain tissue have been recorded using 2D rastering of the cryosectioned tissue with a DESI ion source, and characteristically different distributions in lipids have been noted [30,31].

In this study, a detailed description of the DESI mass spectrometry of some phospholipid and sphingolipid standards of biological interest is presented. The effects of the substrate nature and the solvent composition on lipid signal stability and intensity, along with the types of ions observed and major fragments seen for each of the major physiological phospholipid and sphingolipid classes during DESI-MS and MS/MS analysis, are described. Parallels are drawn between the DESI mass spectra and those recorded by other ionization methods. Next, it is demonstrated that, by addition to the spray solvent of anionic species such as acetate, formate, or bicarbonate, GPCho and SM species can be analyzed in the negative ion mode. Finally, this analysis is extended to the study of physiological phospho/sphingolipids in complex mixtures, specifically from total lipid extract from porcine brain and directly from rat brain cryotome sections.

\section{Experimental}

\section{Mass Spectrometry}

The DESI ion source utilized in these studies was an early Prosolia Inc. prototype and was configured as described previously [30]. The DESI spray was positioned $2 \mathrm{~mm}$ from the surface at an incident angle of $54^{\circ}$ and a low $\left(\mathrm{ca} .10^{\circ}\right)$ collection angle. The same configuration was used for all experiments. The spray was initiated by applying $5 \mathrm{kV}$ to the stainless steel syringe with a solution flow rate of $1.5 \mu \mathrm{L} / \mathrm{min}$. All mass spectra shown were recorded using a Thermo Scientific (Waltham, MA) LTQ and are an average of about 10 consecutive scans.

\section{Lipid Standards}

All lipids used in the reported experiments were purchased from Avanti Polar Lipids (Alabaster, AL) and made up into concentrated solutions $(\mathrm{mg} / \mathrm{mL}$ concentrations) using the manufacturer's suggested solvent systems. The following standards were used: 1-O-1'(Z)-octadecenyl-2-oleoyl-sn-gplycero-3-phosphocholine ( $p$ 18:0/18:1-GPCho), 1-stearoyl-2-palmitoyl-sn-glycero3-phosphocholine (18:0/16:0-GPCho), 1-stearoyl-2-oleoylsn-glycero-3-[phospho-L-serine] (18:0/18:1-GPSer), 1,2dioleoyl-sn-glycero-3-phosphoinositol (18:0/18:0-GPIns), 1-O-1'-(Z)-octadecenyl-2-arachidoyl-sn-glycero3-phosphoethanolamine (p18:0/20:4-GPEtn), total porcine brain extract, 1-palmitoyl-2-oleoyl-sn-glycero-3phosphoethanolamine (16:0/18:1-GPEtn), 1-palmitoyl-2oleoyl-sn-glycero-3-[phospho-rac-(1-glycerol)] (16:0/18:1GPGro), and 1,1',2,2'-tetramyristoyl cardiolipin [(14:0/ 14:0)(14:0/14:0)-CL].

\section{Sample Preparation and Surface Types}

Typically, $2 \mu \mathrm{L}$ of a $100 \mathrm{ng} / \mu \mathrm{L}$ lipid solution in chloroform or 1:1 (vol:vol) methanol/chloroform was spotted on the chosen surface. Glass syringes and vials were used during sample transfer and storage to avoid contact with any plastics to minimize contamination. Following deposition onto the chosen substrate, a heat gun was used to accelerate the drying process. A number of surfaces and solvents were compared by directing the DESI spray at a particular spot and recording the detected ions as a function of time. To study the effect of surface properties, lipid solutions were spotted on polymethyl methacrylate (PMMA), ordinary soda glass, flat polytetrafluoroethylene (PTFE), PTFE printed glass, C18 derivatized glass, gold, and office paper and were analyzed by spraying with 1:1 (vol:vol) methanol/ water. To study the effect of solvent composition, mixtures of methanol and water (pure water, 25\% methanol in water, $50 \%$ methanol, $75 \%$ methanol, and pure methanol) were used to analyze lipid standards on PTFE printed glass. The full mass spectra and MS/MS spectra shown were recorded by spraying 1:1 methanol/ water onto PTFE printed glass slides (Electron Microscopy Sciences, Hatfield, PA). Adducts of GPCho and SM were generated by spraying a solution of $0.1 \%$ (wt:vol) ammonium formate, acetate, or bicarbonate in 1:1 methanol/water. Flat PTFE was purchased from Small Parts, Inc. (Miami Lakes, FL). C18 derivatized glass slides were prepared according to the manufacturer's instructions (AquaSil Siliconizing Fluid; Pierce, Rockford, IL). 


\section{Results and Discussion}

\section{Optimization of Signal Intensity and Stability}

The surface, the spray solvent composition, the analyte properties, and the solvent used to deposit the analyte all require consideration during the development of a DESI method. Each of these factors can affect the signal intensity, signal stability, and the type and extent of adduct formation. The DESI spray solvent is a particularly important variable. Not only must the analyte of interest be at least somewhat soluble in the spray solvent, but the composition of the spray should be such that adequate droplet desorption can occur [32, 33]. Figure 1a illustrates the effect of spray solvent composition on the signal intensity and stability of the positively charged ions generated from plasmalogen GPCho deposited on PTFE printed glass slides. In this experiment, the spray was directed at a particular spot on the surface, and the ion current for the molecular ion was monitored as a function of time. Comparing the five solvents, the signal decays more slowly with time as the proportion of water in the spray solvent is increased. The faster decay of analyte signal when using higher proportions of methanol is probably due to the higher solubility of the analyte in the spray, leading to faster sample depletion. However, the maximum signal intensity is not significantly different between $100 \%$
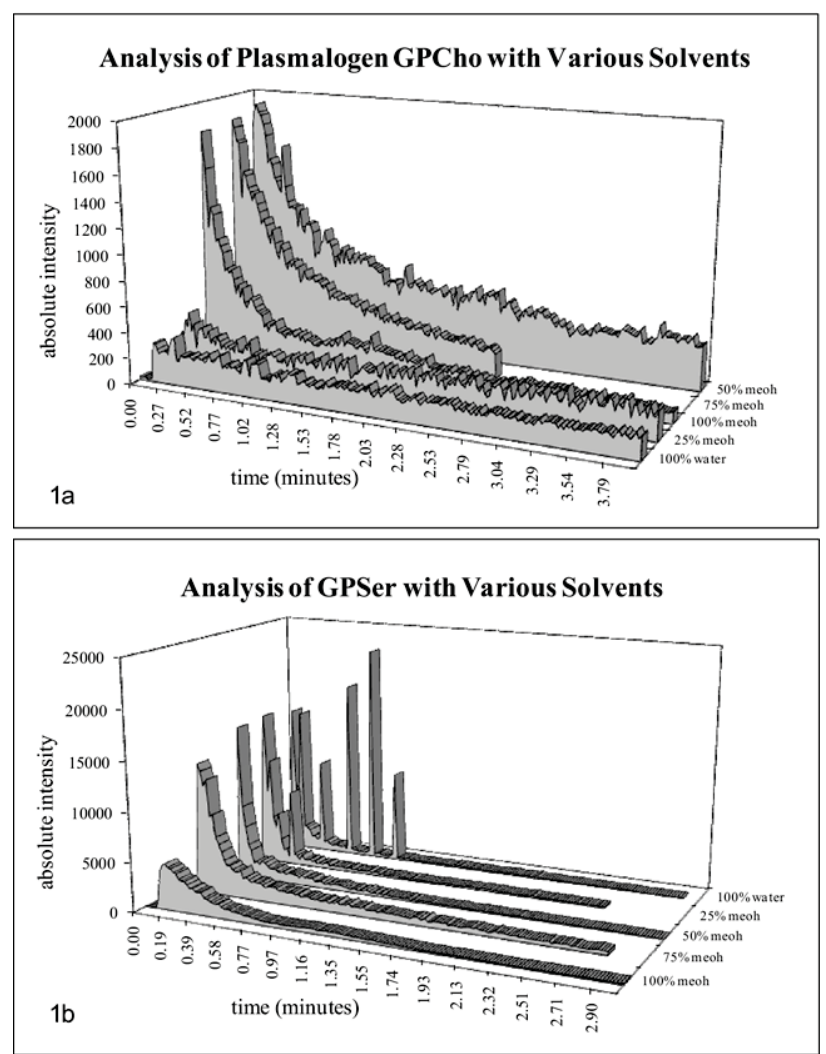

Figure 1. Absolute intensity of (a) plasmalogen GPCho and (b) GPSer molecular ions as a function of time in DESI-MS experiments using different concentrations of methanol in water (meoh: methanol). methanol, $75 \%$ methanol, and 50\% methanol. While one might expect the initial maximum signal to be highest for $100 \%$ methanol due to the higher solubility of the analyte in the spray solvent, other factors arising from changes in solvent properties negate this effect. For example, the spot size and, therefore, the area of the analyte sampled is smaller at higher proportions of organic solvent due to the lower surface tension of the liquid. This hypothesis is supported by the observation that the integrated signal intensity is highest for $50 \%$ methanol, followed by $75 \%$ and $100 \%$ methanol. When the amount of water in the spray exceeds $50 \%$, however, there is a significant decrease in the maximum signal intensity. The reasons for this may include the lower solubility of the analyte in the spray solvent and poor droplet desorption due to unfavorable viscosity and other factors. The role of these physical parameters is evident from fluid mechanics simulations [32]. The same experiment was also performed with phosphatidylserine (GPSer) in the negative ion mode (Figure 1b). Integrated analyte signal is comparable throughout the full range of solvents with the exception of pure methanol, which gives a noticeably lower signal; however, signal stability suffers markedly when spray solvents have higher proportions of water. The time profiles for $100 \%$ water and $25 \%$ methanol show a rapid decay of signal, accompanied by intermittent intense spikes. The poor stability may result from an unstable DESI spray caused by the high proportion of water in the solvent, similar to effects observed in electrospray ionization [34]. The appearance of signal spikes in the negative ion mode but not in the positive ion mode appears to be an example of a general electrospray phenomenon in which the negative ion mode signal is less stable at low analyte concentrations [34]. Analyte signal obtained for spray solvents with greater than $50 \%$ methanol show smooth decays from an initial maximum value. A 1:1 methanol/water (vol:vol) solution typically gives the best combination of signal intensity and stability for phospho- and sphingolipids in both the positive and negative ion modes.

Surface properties represent another important parameter in DESI-MS optimization since they can affect the sensitivity and signal stability. A variety of surfaces has been employed for the analysis of standards by DESI, including PTFE, PMMA, paper, and soda glass. To determine the most appropriate surface for phospholipid analysis, two lipids, plasmalogen GPCho and GPSer, were spotted on a number of different surfaces and the data evaluated based on signal intensity and stability. The surfaces tested were soda glass, C18 coated glass, PTFE printed glass, flat PTFE, PMMA, gold, and office paper. Figure $2 b$ shows the absolute intensity as a function of time for GPSer in the negative ion mode using 1:1 methanol/water as the spray solvent and the same geometry used throughout. The total integrated intensity for the analyte signal is highest for PMMA, followed by PTFE printed glass, flat Teflon, C18 coated glass, and ordinary soda glass. The magni- 
Analysis of Plasmalogen GPCho on Several Surfaces

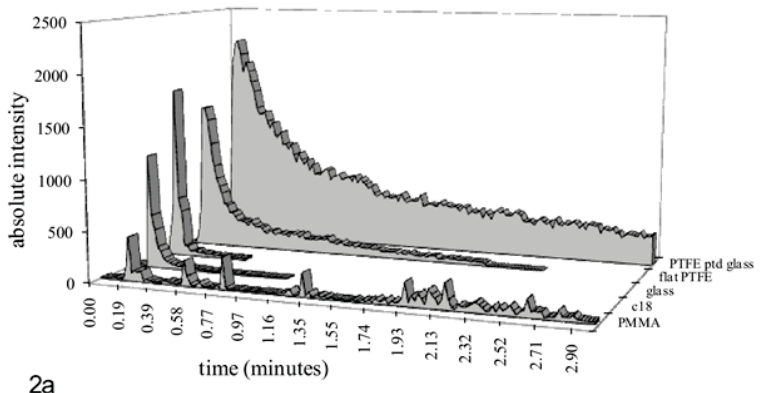

$2 a$

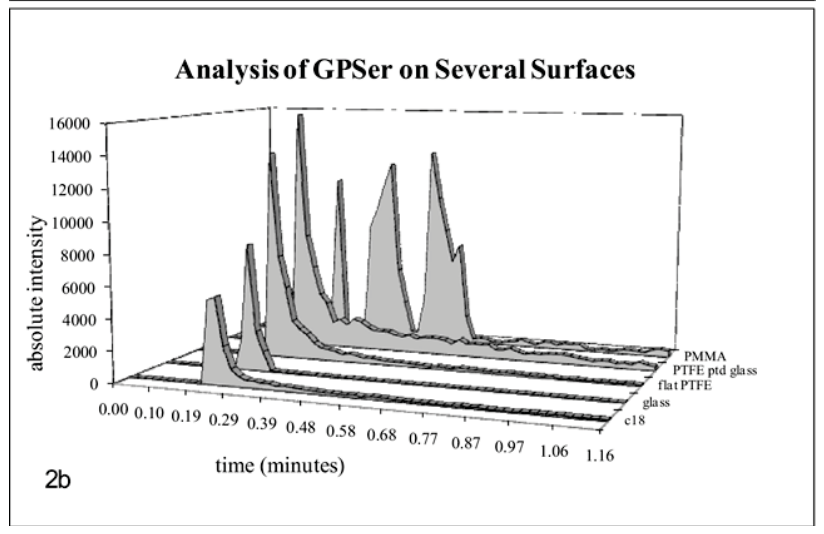

Figure 2. Absolute intensity of (a) plasmalogen GPCho and (b) GPSer molecular ions as a function of time in DESI-MS experiments using several different surfaces (PTFE ptd glass: PTFE printed glass).

tude of the difference in integrated signals between PMMA and PTFE printed glass slides depends on the amount of time over which the signal is integrated because analyte signal is detectable from PTFE printed glass for longer than from PMMA. When the signal is integrated for about $5 \mathrm{~min}$, the total intensity obtained for the two surfaces is similar. GPSer spotted onto soda glass and C18 coated glass gives an integrated intensity of about 10,000 arbitrary counts compared with about 150 for gold and paper, and 20,000 for PTFE and PMMA. The same experiment was also performed in the positive ion mode using plasmalogen GPCho, and it yielded similar results (Figure 2a). PTFE printed glass, which yields primarily the $[\mathrm{M}+\mathrm{H}]^{+}$ion with a much smaller $[\mathrm{M}+\mathrm{Na}]^{+}$peak, gives the highest integrated signal intensity. Since sodium was not added to the spray solvent, the adduct ions were likely a result of adventitious sodium on the surface, in the inlet to the mass spectrometer and/or residual sodium in the spray solvent. The total integrated analyte signal for the other surfaces examined is significantly lower than that obtained from PTFE printed glass. In summary, PTFE printed glass gives intense analyte signal in the positive and negative modes for the polar lipids examined in this study. PMMA also gives intense signal in the negative ion mode; however, as will be discussed below, the stability is rather poor.
In addition to the signal intensity-both maximum and integrated-the signal stability is an important consideration when evaluating the appropriateness of a surface. Figure $2 b$ compares the signal intensities as a function of time recorded for GPSer when analyzed from PTFE printed glass, flat PTFE, C18, soda glass, and PMMA substrates. Each surface showed markedly different signal profiles, with the two PTFE surfaces demonstrating both the slowest decay and the best signal stability. For example, while the PTFE printed slide gives strong lipid signal for more than $5 \mathrm{~min}$ (the duration of the experiment, data not shown), the signal from glass becomes indistinguishable from noise after less than $1 \mathrm{~min}$. The GPSer signal intensity analyzed from PMMA shows poor signal stability compared to the PTFE surfaces, with intense spikes interrupting periods of low signal. Similar trends were seen for plasmalogen GPCho in the positive ion mode (Figure 2a). Signal intensity for GPCho analyzed from PTFE printed glass slides remains strong for more than $5 \mathrm{~min}$, while soda glass, flat PTFE and C18 coated glass do not give signal for more than about $2 \mathrm{~min}$. PMMA signals last for as long as $3 \mathrm{~min}$ with these sample amounts but, as in negative mode, the intensity is unstable. The results presented here are consistent with a study comparing PMMA, flat PTFE, printed PTFE, and a porous PTFE surface for 12 different molecules [35]. In that study, detection limits and signal stability were generally better for the two rough PTFE surfaces compared with PMMA and flat PTFE, particularly the porous PTFE surface.

To conclude this discussion of surface and solvent effects, PTFE printed glass gives the most intense phospholipid signal in the positive ion mode in addition to the most stable and long lasting signals among the surfaces examined. Direct comparison of signal intensity between surfaces can be difficult due to differences in surface properties, particularly variation in the degree of sample spreading upon spotting. Also, it is known that different spray configurations and solvents are appropriate for different surfaces. In general, however, it is evident that best results for spotted lipid samples are obtained using a rough PTFE surface such as that found on PTFE printed glass slides. Nonpolar surfaces minimize interaction with analytes, while rough surfaces have more surface area and also may allow wicking of the analyte into the area of analysis from the surrounding region. Soda glass and PMMA do offer an advantage if the sodium adduct of a molecule rather than the protonated species is desired because both surfaces give almost exclusively the $[\mathrm{M}+\mathrm{Na}]^{+}$ ion. Alternatively, the sodiated species can be obtained by simply doping a small amount of sodium into the DESI spray. This approach is preferable, particularly in applications that require better signal stability, such as quantitation and tandem mass spectrometry. As for choice of solvent for analysis of phospholipid standards, both positive and negative ion data are generally best recorded using 50\% to $75 \%$ methanol in water. The 
exact choice of solvent composition can be varied depending on the application, e.g., higher fractions of water for applications that require long lasting signal, such as $\mathrm{MS}^{\mathrm{n}}$, or a higher proportion of methanol to reduce the DESI spot size for applications requiring higher spatial resolution, such as molecular imaging.

\section{Fragmentation of GPCho in the Positive Ion Mode}

The mass spectrometric analysis of phosphatidylcholines (1 Scheme 1) has been studied extensively using FAB $[9,36]$ and ESI [11, 37-41]. With a quaternary amine in its head group, GPCho ionizes well in the positive ion mode and generally poorly in the negative ion mode. The ionization of GPCho from PTFE printed glass via DESI-MS in the positive ion mode utilizing methanol/water as the spray solvent yields the mass spectrum shown in Figure 3a. The mass spectrum shows the protonated form $[\mathrm{M}+\mathrm{H}]^{+}$of the 18:0/16:0 GPCho molecule as well as the sodiated species at $m / z$ 784. Tandem mass spectrometry of GPCho in the positive ion mode yields limited structural information. The major fragment ion created by collision induced dissociation (CID) of the $[\mathrm{M}+\mathrm{H}]^{+}$peak is the phosphocholine ion at $m / z 184$. The mass difference between this fragment ion and the precursor ion is such that the fragment cannot be detected in a product ion MS/MS scan using a quadruple ion trap under normal operating parameters because fragments with a mass less that about a third of the precursor mass are not normally trapped. By decreasing the frequency of the RF used to excite the GPCho molecular ions generated by DESI, however, an abundant $\mathrm{m} / \mathrm{z} 184$ ion was observed (data not shown). The CID fragments detected in the normal mass range are low abundance ions with a signal to noise ratio of $\sim 2$, and are seen at $m / z 478,496,506$, and 524 (Figure $3 b$ ). These peaks result from neutral losses of a carboxylic acid from the $s n-1$ or $s n-2$ position $(\mathrm{m} / \mathrm{z} 506$ and 478, respectively) and loss of a ketene $(\mathrm{O}=\mathrm{C}=\mathrm{CH}-\mathrm{R})$ from the $s n-1$ or $s n-2$ glycerol position $(\mathrm{m} / \mathrm{z} 524$ and 496, respectively). However, the abundance of these peaks is too low to be used for effective structural determination, and the intensity of the peaks is not increased by increasing the collision energy since ejection of the molecular ion occurs. Collision induced dissociation of GPCho ions generated via ESI in a quadrupole ion trap showed the same collection of low abundance fragment ions [41].

CID of the $[\mathrm{M}+\mathrm{Na}]^{+}$species of phosphatidylcholine, on the other hand, yields more valuable structural information than the $[\mathrm{M}+\mathrm{H}]^{+}$ion. An abundant fragment at $m / z 725$ and a less abundant peak at 601 are seen, presumably due to the loss of $\left(\mathrm{CH}_{3}\right)_{3} \mathrm{~N}$ and the loss of the polar head group via cleavage of the $s n-3$ carbon-oxygen bond, respectively (Figure 3c). Additionally, very low abundance peaks at $m / z 500$ and 528 are detected, corresponding to $\left[\mathrm{M}+\mathrm{Na}-\mathrm{R}_{2} \mathrm{COOH}\right]^{+}$ and $\left[\mathrm{M}+\mathrm{Na}-\mathrm{R}_{1} \mathrm{COOH}\right]^{+}$. This same improvement in fragmentation efficiency has been described in ESI-
MS/MS analysis of GPCho [13, 41], and the fragmentation reported is essentially the same as that observed in DESI-MS. Sphingomyelin (7 Scheme 1), which has the same head group as GPCho but a sphingosine rather than a glycerol backbone, shows a similar MS/MS fragmentation pattern. No major losses were detected for the $[\mathrm{M}+\mathrm{H}]^{+}$ion, while the $[\mathrm{M}+\mathrm{Na}]^{+}$precursor showed an abundant loss of 59, corresponding to the $\left(\mathrm{CH}_{3}\right)_{3} \mathrm{~N}$ from the polar head group. For both $\mathrm{SM}$ and GPCho, therefore, tandem MS of the alkali metal adduct gives more structural information than does the protonated molecule, as has been previously demonstrated with ESI. However, although the $[\mathrm{M}+\mathrm{Na}]^{+}$GPCho ion is more labile under CID conditions than the $[\mathrm{M}+\mathrm{H}]^{+}$ ion, the structure of this phospholipid is still difficult to determine in the positive ion mode using MS/MS because of the low intensity of the fragment ions arising from fatty acid loss.

\section{Fragmentation of Polar Lipids in the Negative Ion Mode}

A number of phospholipids and sphingolipids ionize better in the negative ion mode than in the positive, including GPSer, GPEtn, and ST. In addition to stronger signals, phospholipids also give richer structural information upon collisional activation in the negative ion mode. All of the diacylphospholipids considered in this study show losses of two different neutrals: loss of a neutral carboxylic acid and loss of the corresponding ketene $\left(\mathrm{R}^{\prime} \mathrm{CH}=\mathrm{C}=\mathrm{O}\right)$. These two neutral losses generally occur from both the first $(s n-1)$ and second (sn-2) carbon of the glycerol backbone, allowing for easy structural characterization of the phospholipid. In addition, the fatty acid anions themselves are generally observed and often some loss from the head group occurs, allowing identification of the head group functionality.

Phosphatidylserine (3 Scheme 1), which plays an important role in apoptosis by acting as a marker of apoptotic cells to macrophages, displays exclusively $[\mathrm{M}-\mathrm{H}]^{-}$in the negative ion DESI spectrum, resulting in an ion of $m / z 788$ for 18:0/18:1 GPSer. The most abundant fragment ion in the CID MS/MS spectrum of this molecule is $[\mathrm{M}-\mathrm{H}-87]^{-}$corresponding to the loss of the serine portion of the head group by cleavage of the oxygen-carbon bond (Figure $3 \mathrm{~d}$ ). The next most abundant peaks, at $m / z 417$ and 419 , result from the loss of 87 followed by the loss of one of the two fatty acid chains, with the loss of C18:1 from sn-2 being more probable. Less abundant peaks at $\mathrm{m} / \mathrm{z} 435$ and 437 corresponding to $\left[\mathrm{M}-\mathrm{H}-87-\mathrm{R}^{\prime} \mathrm{CH}=\mathrm{CO}\right]^{-}$, the loss of the serine head group and one of the side chains as an alkyl ketene (e.g., loss of $\mathrm{CH}_{3}\left(\mathrm{CH}_{2}\right)_{15} \mathrm{CH}=\mathrm{C}=\mathrm{O}$ from $s n-1)$, are also seen. Taken together, these fragment ions make identification of the molecular species straightforward. These fragmentations both show a preferential loss of the chain at the sn-2 position, allowing the 


\section{1,2-diacyl glycerophospo-}<smiles>[R]C(=O)OC[C@H](COP([X])(=O)[O-])OC([R])=O</smiles>

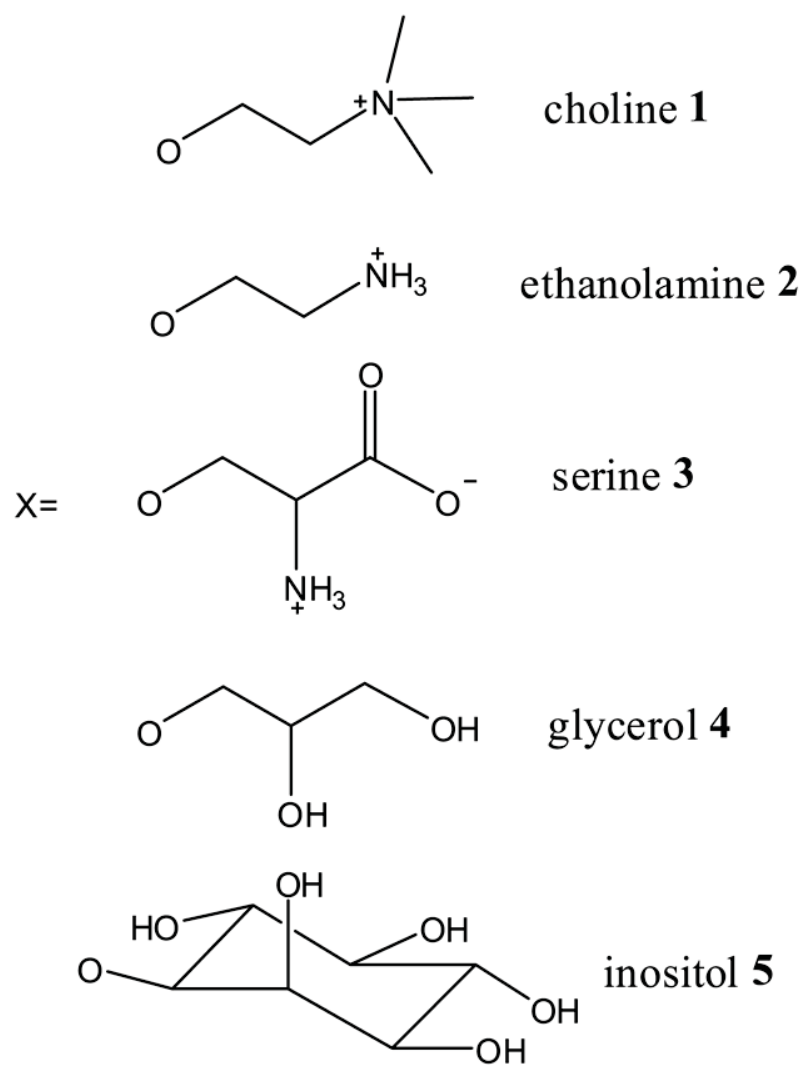

sphingolipids

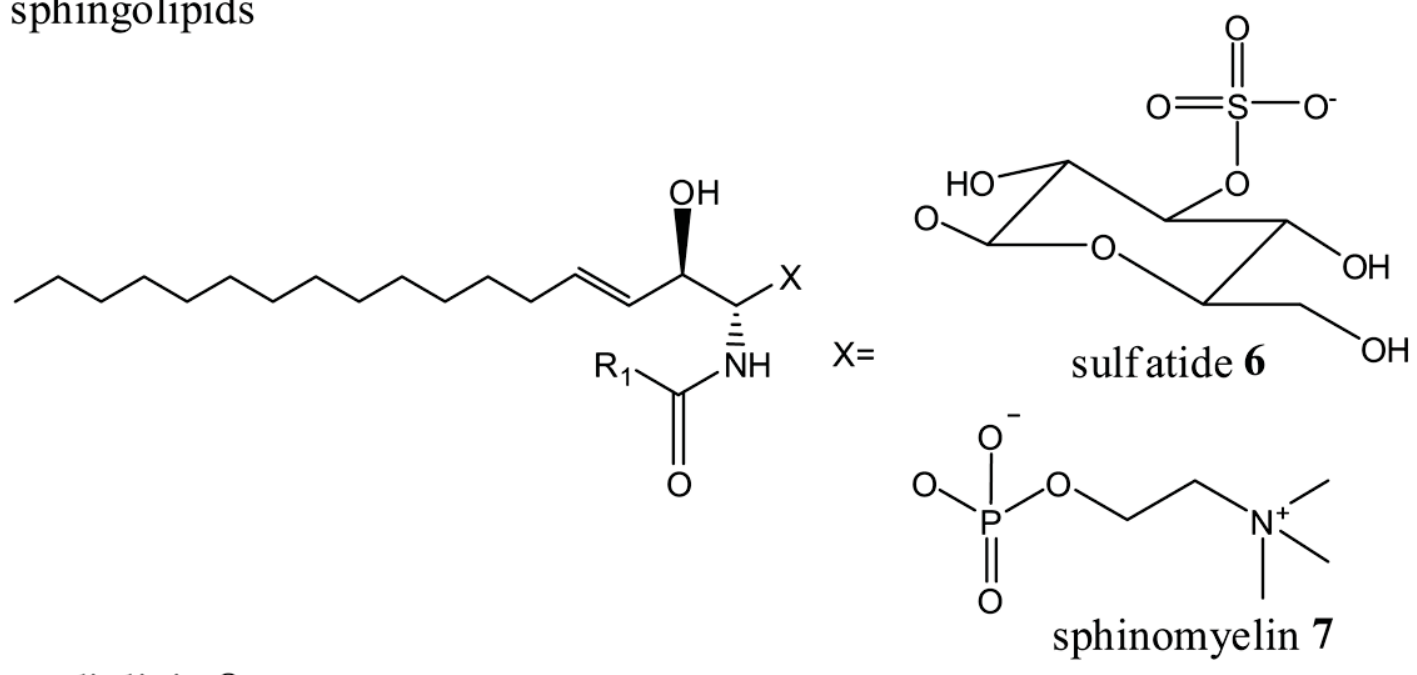

cardiolipin 8<smiles>[R]C(=O)OC[C@H](COP(=O)([O-])OCC(O)COP(=O)([O-])OC[C@@H](COC([R])=O)OC([R])=O)OC([R])=O</smiles> 

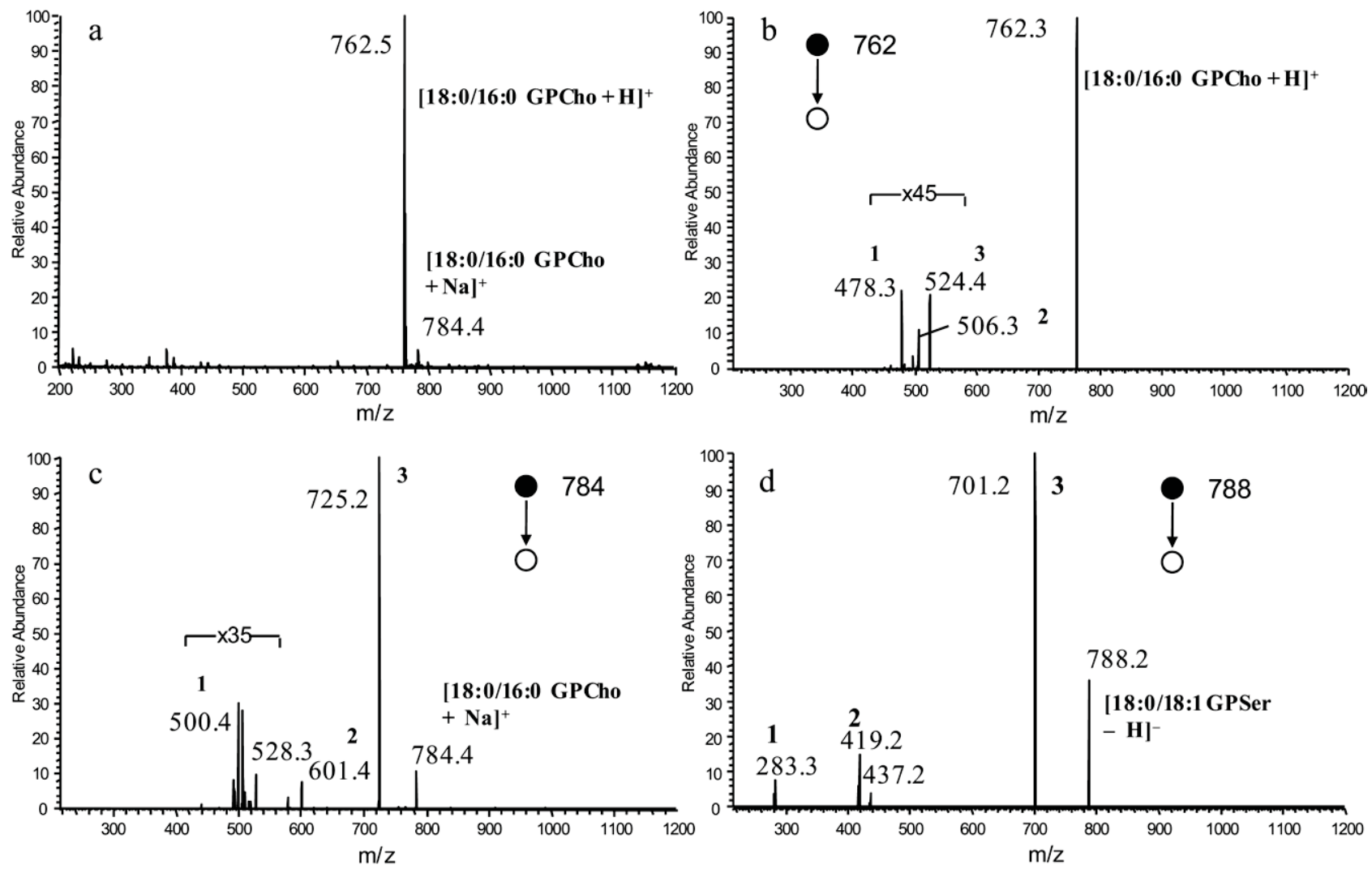

Figure 3. (a) Full scan DESI mass spectrum of 16:0/18:0 GPCho. (b) The MS/MS of the GPCho $[\mathrm{M}+\mathrm{H}]^{+}$ion; (1) $\left[\mathrm{M}+\mathrm{H}-\mathrm{C}_{17} \mathrm{H}_{35} \mathrm{COOH}\right]^{+}$; (2) $\left[\mathrm{M}+\mathrm{H}-\mathrm{C}_{15} \mathrm{H}_{31} \mathrm{COOH}\right]^{+}$; (3) $[\mathrm{M}+\mathrm{H}-$ $\left.\mathrm{C}_{14} \mathrm{H}_{29} \mathrm{CH}=\mathrm{C}=\mathrm{O}\right]^{+}$. (c) The MS/MS of [GPCho $\left.+\mathrm{Na}\right]^{+}$; (1) $\left[\mathrm{M}+\mathrm{Na}-\mathrm{C}_{17} \mathrm{H}_{35} \mathrm{COOH}\right]^{+}$(2) $[\mathrm{M}+$ $\left.\mathrm{Na}-\mathrm{C}_{5} \mathrm{H}_{13} \mathrm{NPO}_{4}\right]^{+}$; (3) $\left[\mathrm{M}+\mathrm{Na}-\left(\mathrm{CH}_{3}\right)_{3} \mathrm{~N}\right]^{+}$. (d) MS/MS of the [18:0/18:1 GPSer $\left.-\mathrm{H}\right]^{-}$ion; (1) $\left[\mathrm{C}_{17} \mathrm{H}_{35} \mathrm{COO}^{-}\right.$; (2) $\left[\mathrm{M}-\mathrm{H}-\mathrm{C}_{3} \mathrm{H}_{5} \mathrm{NO}_{2}-\mathrm{C}_{17} \mathrm{H}_{33} \mathrm{COOH}\right]$; (3) $\left[\mathrm{M}-\mathrm{H}-\mathrm{C}_{3} \mathrm{H}_{5} \mathrm{NO}_{2}\right]^{-}$.

intensity ratio to be used to assign the two fatty acid chains to either the $s n-1$ or $s n-2$ glycerol carbon. However, while the ratio between $s n-1$ and $s n-2$ loss for GPSer and other lipids may be used for structural determination, previous studies with ESI and FAB have concluded that the $s n-1 / s n-2$ abundance ratio is affected by the nature of the side chains (length and degree of unsaturation), the collision energy, and other instrument parameters [43-45]. Therefore, care must be taken when using the intensity ratios of these fragment ions for structural determinations. The last set of fragment ions observed for the CID of GPSer are the carboxylate anions at $\mathrm{m} / \mathrm{z} 283$ and 281, with that arising from the C18:0 fatty acid anion from $s n-1$ being more intense. It has been suggested that the pathway involving fatty acid anion lost from $s n-1$ is favored because the fatty acid anions are formed primarily from further decomposition of $[\mathrm{M}-\mathrm{H}-\mathrm{RCOOH}]^{-}$[42].

DESI-MS/MS of phospholipids gives a wealth of structural information, particularly in the negative ion mode. Fragmentation data obtained for a number of polar lipid classes using DESI-MS are shown in Table 1. While little information regarding the fatty acid side chains can be gleaned in the positive ion mode, MS/MS of phospholipids in the negative ion mode gives abun- dant peaks for the neutral loss of the fatty acid side chains and/or strong signal for the fatty acid anions themselves. The relative intensity of the fatty acid losses can be used to place the fatty acids at the $s n-1$ or $s n-2$ glycerol position so long as standard analysis is first carried out and instrumental parameters are controlled.

\section{Adduct Formation and Fragmentation of GPCho and SM in the Negative Ion Mode}

GPCho and SM cannot be analyzed in the negative ion mode under typical DESI or ESI conditions because of the permanent positive charge located on the quaternary amine in the head groups of both lipids. These lipids have been successfully analyzed in the negative ion mode with FAB and ESI-MS via adduct formation between the lipid and some anionic species present in solution with the analyte $[11,44]$. Likewise, negative ions of GPCho and SM molecular species can be generated by adduct formation when appropriate anions are present in the nebulizing DESI spray; acetate, formate, and bicarbonate ions are used successfully in this study. Figure $4 \mathrm{a}$ and $\mathrm{b}$ show the mass spectra of 18:0/16:0 GPCho detected from PTFE printed glass in positive ion 


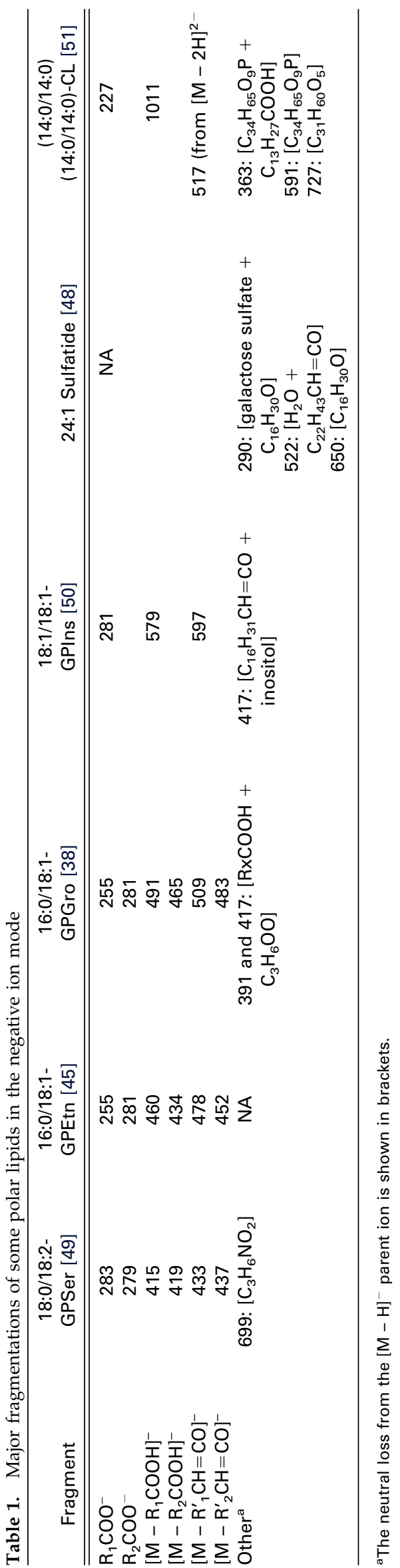

mode and the acetate adducts in the negative mode, respectively. A 1:1 solution of methanol/water (vol/ vol) with $0.1 \%$ ammonium formate, ammonium acetate, or ammonium bicarbonate (by mass) works well for most such samples.

There are a number of advantages to analyzing GPCho and SM species in the negative rather than positive ion mode. First, as will be discussed further below, GPCho and SM can be analyzed in a single experiment in the presence of more acidic lipids like ST and GPSer. This is a significant advantage in terms of improving throughput and when the sample can only be analyzed once as in imaging applications. Second, it is difficult to identify or determine the structure of GPCho molecules via tandem mass spectrometry experiments done on the $[\mathrm{M}+\mathrm{H}]^{+}$or $[\mathrm{M}+\mathrm{Na}]^{+}$ions in the positive ion mode. MS/MS of the $[\mathrm{M}+\mathrm{H}]^{+}$ion does not yield any abundant fragments aside from the choline ion itself, while the $[\mathrm{M}+\mathrm{Na}]^{+}$ion of GPCho shows mainly the loss of $\left(\mathrm{CH}_{3}\right)_{3} \mathrm{~N}$ upon collision induced dissociation. For this ion, the fragment ions arising from side loss are very unfavorable in the positive ion mode and extensive signal averaging is required to get a consistent ratio between the $s n-1$ and $s n-2$ fatty acids [13, 41]. If signal strength is low or transient, this is often not possible, making firm structural assignment problematic. In the negative ion mode, on the other hand, tandem mass spectrometry of GPCho adducts of formate or acetate yields a wealth of information. The MS/MS spectrum of the acetate adducts of GPCho 18:0/16:0 shows a peak at $m / z 746$, corresponding to loss of methyl acetate arising from an intermolecular $\mathrm{S}_{\mathrm{N}} 2$ reaction between the choline head group and the adduct (Figure 4c) [46]. The $\mathrm{MS}^{3}$ spectrum of $\mathrm{m} / \mathrm{z} 746$ shows peaks at $m / z 283$ and 255 , confirming the identity of the fatty acids attached to the glycerol backbone (Figure $4 \mathrm{~d}$ ). The other peaks, at $\mathrm{m} / \mathrm{z} 480$ and 508, result from loss of a ketene from $s n-2$ and $s n-1$, respectively. It should be noted that the absolute signal intensity of GPCho adducts in the negative ion mode is somewhat lower (about half) than the corresponding $[\mathrm{M}+\mathrm{H}]^{+}$ and $[\mathrm{M}+\mathrm{Na}]^{+}$signals in the positive ion mode. However, the $2 \times$ increase in signal intensity in the positive ion mode was not enough to overcome the lower fragment ion intensity compared to the negative ion mode. Therefore, for structural characterization of GPCho by DESI, negative mode analysis of adduct ion is generally superior to positive mode analysis of the $\mathrm{M}$ $+\mathrm{H}$ or $\mathrm{M}+\mathrm{Na}$ ions. However, experiments using ESI have demonstrated that it is possible to get good structural information of GPCho ions in the positive ion mode by formation of $\mathrm{Li}^{+}$adducts [37]. This approach would also require the addition of an ionic species to the solvent, but would not have the added advantages of negative mode analysis such as simultaneous detection of more acidic polar lipids. Use of $\mathrm{Li}^{+}$adducts in DESI-MS may be more sensitive than formation of formate or acetate adducts. 

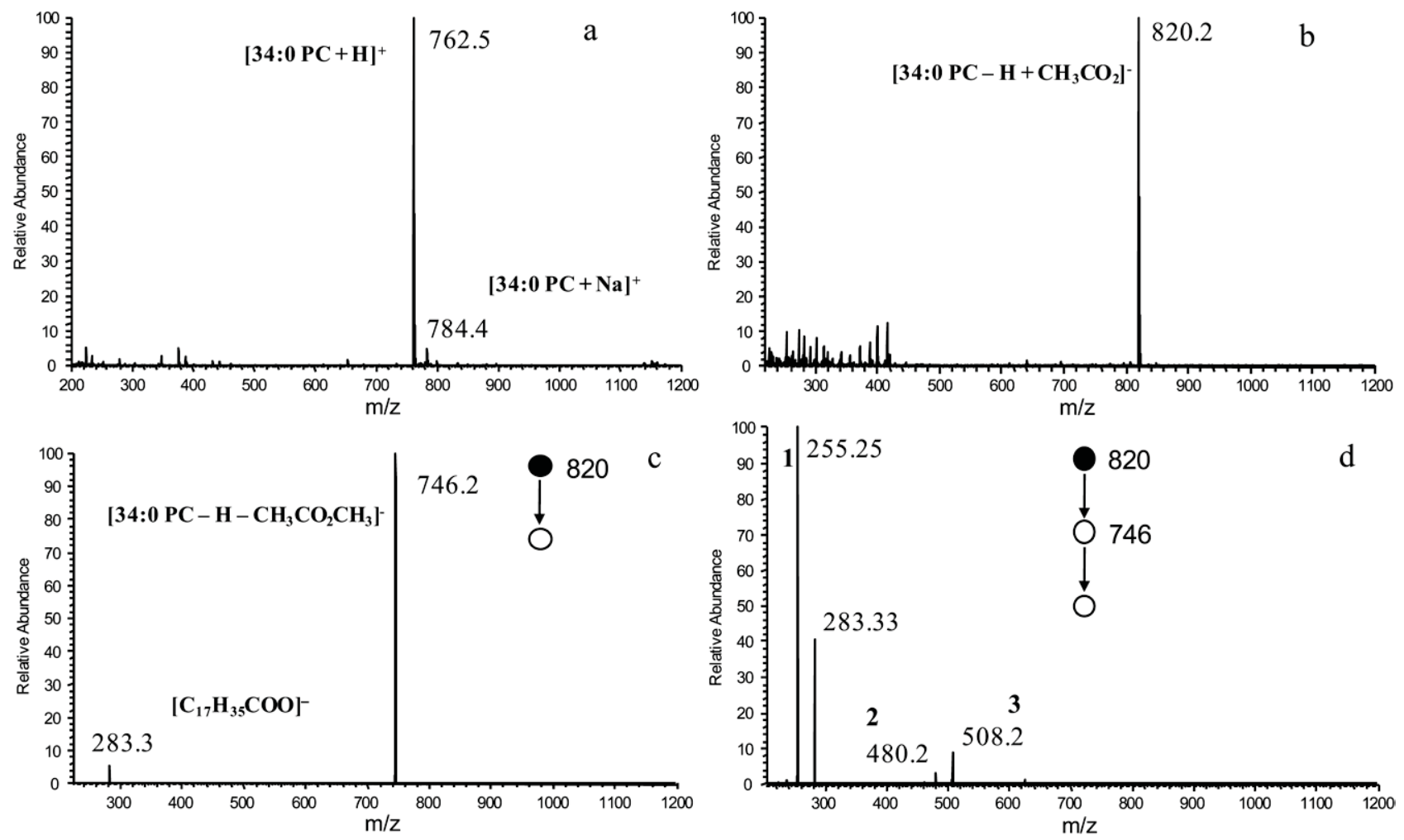

Figure 4. (a) DESI mass spectrum of 16:0/18:0 GPCho in positive mode. (b) Full MS of acetate adducted GPCho in negative ion mode. (c) MS/MS of [34:0 GPCho $-\mathrm{H}+\mathrm{OAc}^{-}$showing loss of methylacetate $(820 \rightarrow 746)$. (d) $\mathrm{MS}^{3}$ on $\left[\mathrm{M}-\mathrm{H}-\mathrm{CH}_{3} \mathrm{CO}_{2} \mathrm{CH}_{3}\right]^{-}$; (1) $\left[\mathrm{C}_{15} \mathrm{H}_{31} \mathrm{COO}\right]^{-}$; (2) [746 $\left.\mathrm{C}_{16} \mathrm{H}_{33} \mathrm{CH}=\mathrm{C}=\mathrm{O}\right]^{-}$; (3) $\left[746-\mathrm{C}_{14} \mathrm{H}_{29} \mathrm{CH}=\mathrm{C}=\mathrm{O}^{-}\right.$.

\section{Analysis of Complex Mixtures}

The phospholipid region of the negative ion mode DESI MS spectrum obtained from total lipid extract from porcine brain is shown in Figure 5a. As with the analysis of GPSer standards in the negative ion mode, the most intense and stable signal is obtained when the lipid mixture is spotted on PTFE printed glass and analyzed with $50 \%$ to $70 \%$ methanol/water. The mass spectrum is dominated in large part by phosphatidylserines, phosphatidylinositols, and sulfatides. As with standard compounds, the exact identity of a particular lipid peak can be determined using tandem mass spectrometry. Figure $5 b$ shows the MS/MS spectrum of a sulfatide sphingolipid (6 Scheme 1 ) at $m / z$ 888. Sulfated galactocerebrosides (sulfatides), known especially for their role in the myelin sheath of the nervous system [47], differ from the lipids discussed thus far in that they do not contain a glycerol-phosphate backbone but instead possess a sphingosine base. A fatty acid chain, which can be unsaturated and/or hydroxylated, is attached to the nitrogen of the sphingosine backbone via an amide bond. Sulfatide fragmentation, detailed in reference [48] for ESI-MS/MS on a triple quadrupole, shows several complex processes. Collision induced dissociation of DESI generated ion of $\mathrm{m} / \mathrm{z} 888$ gives rise to an abundant peak at $m / z 522$, corresponding to the loss of water and the amide linked ketene by cleavage of the amide bond. The fragment of $\mathrm{m} / \mathrm{z} 390$ arises from cleavage of the $\mathrm{C} 2$ to $\mathrm{C} 3$ bond of the sphingosine backbone along with loss of the head group via cleavage of the C1-O bond. Finally, the fragment ion of $m / z$ 650 comes from loss of the long-chain base after the second carbon. These fragment ions are sufficient to identify the ion at $\mathrm{m} / \mathrm{z} 888$ as a sulfatide with a $24: 1$ nonhydroxylated fatty acid chain. All of the other peaks in the lipid profile of the brain extract can likewise be identified based on their CID spectra.

The ions detected from the brain extract in the positive ion mode by spraying methanol/water are shown in Figure $5 c$. The primary species detected are phosphatidylcholines, which are expected to be abundant in the brain extract and to ionize well in the positive ion mode. Figure 5d shows the MS/MS spectrum of $\mathrm{m} / \mathrm{z} 810$. The abundant fragment ions at [M $59]^{+}$and $[\mathrm{M}-183]^{+}$indicate that the precursor ion is a GPCho alkali metal adduct. Further structural information is limited, however, due to the low abundance of the fragment ions arising from fatty acid loss.

The corresponding negative ions detected by spraying methanol/water with $0.1 \%$ ammonium formate are shown in Figure 5e. In addition to the acidic phospholipids and sphingolipids detected when spraying only methanol/water, formate adducts of GPCho species are also detected. Addition of anionic species to the spray 

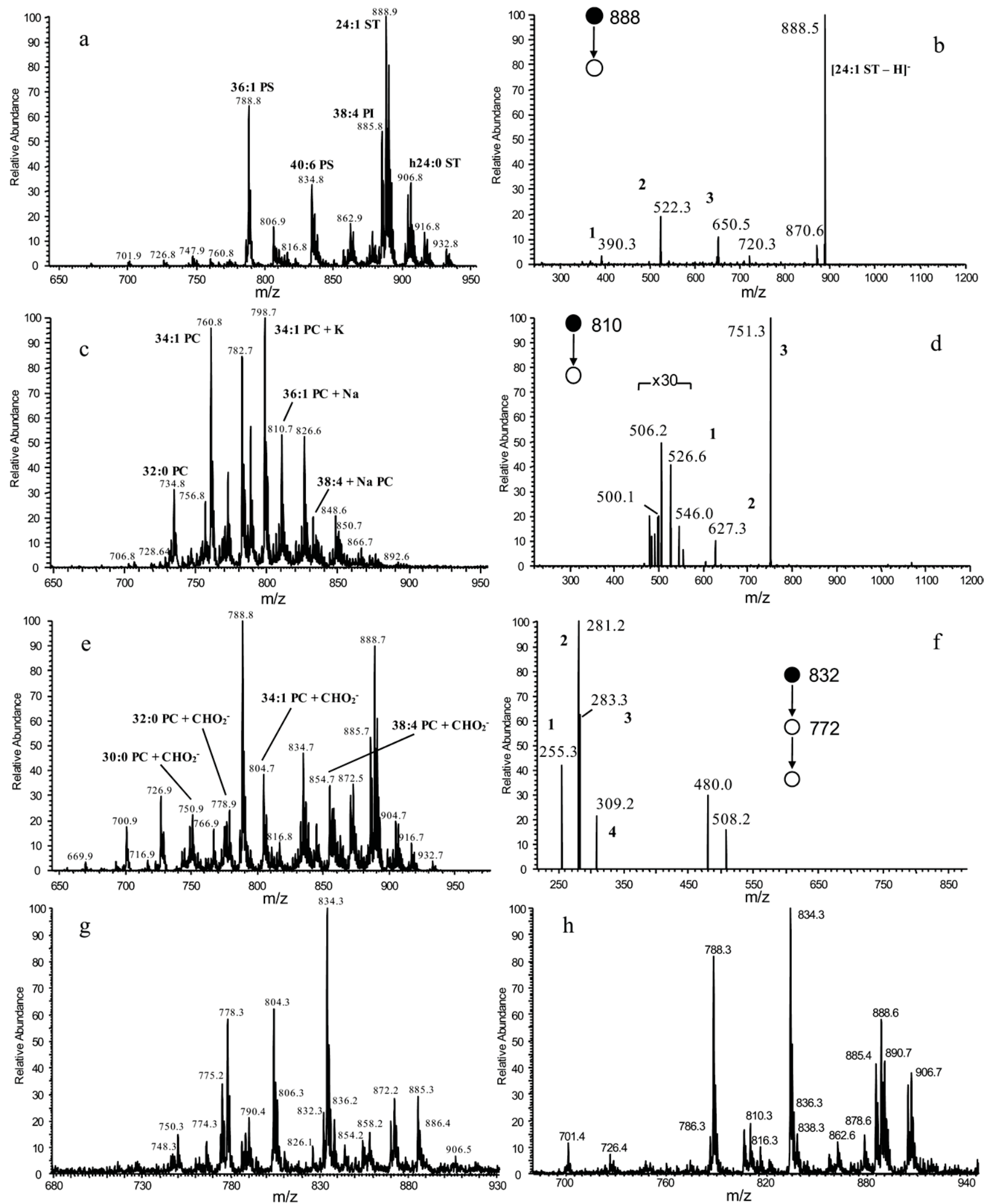

Figure 5. (a) Phospholipid and sphingolipid profile of porcine brain extract in negative mode spraying 1:1 methanol/water. (b) MS/MS of $m / z 888$ from (a); (1) $\left[\mathrm{M}-\mathrm{H}-\text { galactose sulfate }-\mathrm{C}_{16} \mathrm{H}_{30} \mathrm{O}\right]^{-}$; (2) $[\mathrm{M}-\mathrm{H}-$ $\left.\mathrm{H}_{2} \mathrm{O}-\mathrm{C}_{22} \mathrm{H}_{43} \mathrm{CH}=\mathrm{C}=\mathrm{O}\right]^{-}$; (3) $\left[\mathrm{M}-\mathrm{H}-\mathrm{C}_{16} \mathrm{H}_{30} \mathrm{O}\right]^{-}$. (c) Positive ion mode spraying 1:1 methanol/water. (d) MS/MS of $m / z 810$ from (c); (1) $\left[\mathrm{M}+\mathrm{Na}-\mathrm{C}_{17} \mathrm{H}_{35} \mathrm{COOH}\right]^{+}$; (2) $\left[\mathrm{M}+\mathrm{Na}-\mathrm{C}_{5} \mathrm{H}_{13} \mathrm{PO}_{4}\right]^{+}$; (3) $[\mathrm{M}+\mathrm{Na}-$ $\left.\left(\mathrm{CH}_{3}\right)_{3} \mathrm{~N}\right]^{+}$. (e) Negative ion mode of brain extract spraying 1:1 methanol/water with $0.1 \%$ ammonium formate. (f) $\mathrm{MS}^{3}$ of $m / z 832 \rightarrow 772$ from (e); (1) $\left[\mathrm{C}_{15} \mathrm{H}_{31} \mathrm{COO}\right]^{-}$; (2) $\left[\mathrm{C}_{17} \mathrm{H}_{33} \mathrm{COO}\right]^{-}$; (3) $\left[\mathrm{C}_{17} \mathrm{H}_{35} \mathrm{COO}\right]^{-}$; (4) $\left[\mathrm{C}_{19} \mathrm{H}_{37} \mathrm{COO}\right]^{-}$. The last two spectra show direct analysis of rat brain cryotome section with 1:1 methanol/water as the spray solvent (g) with and (h) without $0.1 \%$ ammonium formate. 
solvent therefore allow GPCho and SM species, which normally only ionize in the positive ion mode, to be characterized in the negative ion mode along with the many lipids, such as GPSer and GPIns, which do not ionize well in the positive ion mode. Significantly more chemical information is attainable in a single experiment when formate is doped into the spray, a technique that could be particularly useful when carrying out molecular imaging of tissue where a given sample can only be analyzed once. One potentially complicating factor is that the spectra may change as a result of changes in the $\mathrm{pH}$ and ionic strength of the spray solvent. For example, two GPEtn species that are minor components in the normal negative ion mode spectrum $(\mathrm{m} / \mathrm{z} 700$ and 726 in Figure 5a) give much larger peaks upon the addition of formate to the spray solvent (Figure 5e). Nonspecific enhancement or suppression of some lipid ions can be beneficial or detrimental depending on the situation and will require attention during method development.

Tandem mass spectrometry can be easily used to detect formate adducts in a complex mixture such as that analyzed in Figure 5e, because formate adduct ions show a loss of 60 upon collisional activation, corresponding to methyl formate. Triple stage $\mathrm{MS}^{3}$ experiments are generally required to gain structural information about the phospholipid. Figure $5 f$ shows the $\mathrm{MS}^{3}$ spectrum of a formate adduct ion with $\mathrm{m} / \mathrm{z} 832$ detected from brain extract when spraying formate doped methanol/water. Four different fatty acid fragments are detected, indicating that $m / z 832$ is, at least, a mixture of 18:0/18:1 GPCho and 20:1/16:0 GPCho. The position of the fatty acids is based on the ratio between the peak intensities and is ambiguous in this case because the factors noted previously were not controlled for.

Table 2 gives the identity of the major peaks detected in the positive ion mode and the corresponding formate adduct peaks in the negative ion mode for this lipid mixture. All of the major lipid peaks in positive mode are $[\mathrm{M}+\mathrm{H}]^{+}$or $[\mathrm{M}+\mathrm{Na}]^{+} /[\mathrm{M}+\mathrm{K}]^{+}$phosphatidylcholine peaks as determined by MS/MS (alkali metal GPCho adducts give a loss of 59 while the molecular ion does not). None of the major peaks can be due to sphingomyelin because all have an even $\mathrm{m} / \mathrm{z}$; sphingomyelin contains two nitrogens, and its $[\mathrm{M}+\mathrm{H}]^{+}$or $[\mathrm{M}+\mathrm{Na}]^{+}$ions will therefore have an odd numbered $m / z$ value. None are PE because the characteristic loss of 141 was not seen upon CID. Formate adduct peaks in the negative ion mode were identified by their characteristic loss of $60 . \mathrm{MS}^{3}$ experiments on the $[\mathrm{M}-60]^{-}$ion were used to identify the fatty acid side chains. Several of the formate adduct ions detected from the brain extract, such as $m / z 776,832$, and 854 , actually include two or more isobaric GPCho species that can only be differentiated with tandem mass spectrometry. In some cases, the formate adduct GPCho may have the same nominal mass as another polar lipid. For example, the formate adduct, [36:0 GPCho $\left.+\mathrm{CHO}_{2}\right]^{-}$with a molecular formula of $\left[\mathrm{C}_{45} \mathrm{H}_{89} \mathrm{NO}_{10} \mathrm{P}\right]^{-}$coincides in mass with another phospholipid detected in the negative ion mode, [40:6 GPSer $-\mathrm{H}]^{-}$with a molecular formula of $\left[\mathrm{C}_{46} \mathrm{H}_{77} \mathrm{NO}_{10} \mathrm{P}\right]^{-}$. Overlapping peaks can be differentiated using tandem mass spectrometry or with a higher resolution instrument than that used in this study. Also, a different anionic species such as acetate or bicarbonate can be substituted for formate. Finally, lipids without a quaternary amine, like GPSer and ST, did not form formate adducts to any measurable degree.

This type of methodology can be extended to direct tissue analysis as shown in Figure $5 \mathrm{~g}$ for rat brain cryotome sections. Figure $5 \mathrm{~h}$ shows the lipid profile obtained from a similar tissue section without formate ions present in the spray solvent for comparison. The individual formate ions have not yet been confirmed by tandem mass spectrometry but, as expected, the major formate adduct peaks detected from porcine brain extract are also seen from direct analysis of the rat brain sections.

Table 2. Formate adduct peaks detected in the negative ion mode

\begin{tabular}{cllr}
\hline Adduct lon & \multicolumn{1}{c}{ Corresponding +ve mode ions } & MS $^{3}$ fatty acid ions & Lipid $^{\text {a }}$ \\
\hline \hline 748 & $726[\mathrm{M}+\mathrm{Na}]^{+}, 742[\mathrm{M}+\mathrm{K}]^{+}$ & 227,253 & $14: 0 / 16: 1 \mathrm{GPCho}$ \\
750 & $728[\mathrm{M}+\mathrm{Na}]^{+}, 744[\mathrm{M}+\mathrm{K}]^{+}$ & 227,255 & $14: 0 / 16: 0 \mathrm{GPCho}$ \\
776 & $732[\mathrm{M}+\mathrm{H}]^{+}, 754[\mathrm{M}+\mathrm{Na}]^{+}, 770[\mathrm{M}+\mathrm{K}]^{+}$ & $227,253,255,281$ & $16: 1 / 16: 0 \mathrm{GPCho}$ \\
& & & $14: 0 / 18: 1 \mathrm{GPCho}$ \\
778 & $734[\mathrm{M}+\mathrm{H}]^{+}, 756[\mathrm{M}+\mathrm{Na}]^{+}, 772[\mathrm{M}+\mathrm{K}]^{+}$ & $16: 0 / 16: 0 \mathrm{GPCho}$ \\
804 & $760[\mathrm{M}+\mathrm{H}]^{+}, 782[\mathrm{M}+\mathrm{Na}]^{+}, 798[\mathrm{M}+\mathrm{K}]^{+}$ & 255 & $16: 0 / 18: 1 \mathrm{GPCho}$ \\
830 & $786[\mathrm{M}+\mathrm{H}]^{+}, 808[\mathrm{M}+\mathrm{Na}]^{+}, 824[\mathrm{M}+\mathrm{K}]^{+}$ & 255,281 & $18: 0 / 18: 2 \mathrm{GPCho}$ \\
832 & $788[\mathrm{M}+\mathrm{H}]^{+}, 810[\mathrm{M}+\mathrm{Na}]^{+}, 826[\mathrm{M}+\mathrm{K}]^{+}$ & 279,283 & $18: 1 / 18: 0 \mathrm{GPCho}$ \\
& & $255,281,283,309$ & $20: 1 / 16: 0 \mathrm{GPCho}$ \\
834 & $790[\mathrm{M}+\mathrm{H}]^{+}, 812[\mathrm{M}+\mathrm{Na}]^{+}$, & $255,283,311$ & $18: 0 / 18: 0 \mathrm{GPCho}$ \\
& $828[\mathrm{M}+\mathrm{K}]^{+}$ & $20: 0 / 16: 0 \mathrm{GPCho}$ \\
854 & $832[\mathrm{M}+\mathrm{Na}]^{+}$ & $255,283,303,331$ & $18: 0 / 20: 4 \mathrm{GPCho}$ \\
& & & $16: 0 / 22: 4 \mathrm{GPCho}$ \\
\hline
\end{tabular}

aLipid assignment is based on the FA anions observed and the parent mass. The position of the FAs (i.e., sn-1 versus sn-2) is ambiguous. 


\section{Conclusions}

DESI is an effective means of ionizing phospholipids and of characterizing them using tandem mass spectrometry. While ESI is a superior method for the analysis of extracted and separated phospholipids, DESI will likely find a role for direct detection of polar lipids from tissue and other surfaces. With this in mind, practical aspects of DESI analysis of polar lipids, structural information that can be gleaned using DESI-MS ${ }^{n}$, and further areas of inquiry that DESI-MS opens up that have not been reported by other DI techniques (i.e., use of reagents in the spray solvent to analyze PC and SM in negative mode), were presented. The analysis of standards and lipid extracts is usually best carried out by spotting the analytes onto rough nonpolar surfaces such as that found on PTFE printed glass slides and spraying with 1:1 methanol/water. Phospholipids are generally best analyzed in the negative ion mode, both because most of these lipids ionize much more effectively and because more complete structural information is obtained upon collisional activation. It is also significant that negative ion spectra of complex materials are generally simpler than the positive ion counterparts. Once desorbed from the surface, most phospholipids can be unequivocally identified via MS/MS and $\mathrm{MS}^{3}$ as has been demonstrated in this study and in previous work using ESI and other ionization methods. Finally, by adding additional reagents to the spray solution, such as formate or other anionic species, lipids containing a permanent positive charge can be ionized in the negative ion mode. This capability presents the advantage of analyzing many different lipid species directly from tissue sections in one ionization mode. This application is potentially valuable when performing DESI imaging experiments.

\section{Acknowledgments}

The authors acknowledge support from the National Science Foundation, Prosolia, Inc., Indianapolis, IN, and the Indiana Twenty-First Century Technology and Research Fund.

\section{References}

1. Vance, D. E.; Vance, J. Biochemistry of Lipids, Lipoproteins, and Membranes, 3rd ed.; Elsevier: New York; 1996, pp. 28-36.

2. Crawford, C. G.; Plattner, R. D. Ammonia Chemical Ionization MassSpectrometry of Intact Diacyl Phosphatidylcholine. J. Lipid Res. 1983, 24 , 456-460.

3. Bisseret, P.; Nakatani, Y.; Ourisson, G.; Hueber, R.; Teller, G. Ammonia Chemical Ionization Mass-Spectrometry of Lecithins on a Gold Support. Chem. Phys. Lipids 1983, 33, 383-392.

4. Ayanoglu, E.; Wegmann, A.; Pilet, O.; Marbury, G. D.; Hass, J. R.; Djerassi, C. Mass-Spectrometry of Phospholipids. Some Applications of Desorption Chemical Ionization and Fast Atom Bombardment. J. Am. Chem. Soc. 1984, 106, 5246-5251.

5. Jungalwala, F. B.; Evans, J. E.; McCluer, R. H. Compositional and Molecular-Species Analysis of Phospholipids by High-Performance Liquid-Chromatography Coupled with Chemical Ionization MassSpectrometry. J. Lipid Res. 1984, 25, 738-749.

6. Chilton, F. H.; Murphy, R. C. Fast-Atom-Bombardment Analysis of Arachidonic Acid-Containing Phosphatidylcholine Molecular-Species. Biomed. Environ. Mass Spectrom. 1986, 13, 71-76.

7. Jensen, N. J.; Tomer, K. B.; Gross, M. L. FAB MS/MS for Phosphatidylinositol, -Glycerol, Phosphatidylethanolamine, and Other Complex Phospholipids. Lipids 1987, 22, 480-489.
8. Kayganich, K. A.; Murphy, R. C. Fast-Atom-Bombardment Tandem Mass-Spectrometric Identification of Diacyl, Alkylacyl, and Alk-1Enylacyl Molecular-Species of Glycerophosphoethanolamine in Human Polymorphonuclear Leukocytes. Anal. Chem. 1992, 64, 2965-2971.

9. Murphy, R. C.; Harrison, K. A. Fast Atom Bombardment Mass Spectrometry of Phospholipids. Mass Spectrom. Rev. 1994, 13, 57-75.

10. Duffin, K. L.; Henion, J. D.; Shieh, J. J. Electrospray and Tandem Mass-Spectrometric Characterization of Acylglycerol Mixtures That Are Dissolved in Nonpolar Solvents. Anal. Chem. 1991, 63, 1781-1788.

11. Kerwin, J. L.; Tuininga, A. R.; Ericsson, L. H. Identification of Molecular-Species of Glycerophospholipids and Sphingomyelin Using Electrospray Mass-Spectrometry. I. Lipid Res. 1994, 35, 1102-1114.

12. Kim, H. Y.; Wang, T. C. L.; Ma, Y. C. Liquid-Chromatography MassSpectrometry of Phospholipids Using Electrospray-Ionization. Anal. Chem. 1994, 66, 3977-3982.

13. Han, X. L.; Gross, R. W. Structural Determination of Picomole Amounts of Phospholipids Via Electrospray Ionization Tandem Mass Spectrometry. J. Am. Soc. Mass Spectrom. 1995, 6, 1202-1210.

14. Cheng, C. F.; Gross, M. L. Complete Structural Elucidation of Triacylglycerols by Tandem Sector Mass Spectrometry. Anal. Chem. 1998, 70, 4417-4426.

15. Hsu, F. F.; Turk, J. Structural Characterization of Triacylglycerols as Lithiated Adducts by Electrospray Ionization Mass Spectrometry Using Low-Energy Collisionally Activated Dissociation on a Triple Stage Quadrupole Instrument. J. Am. Soc. Mass Spectrom. 1999, 10, 587-599.

16. Ivanova, P. T.; Cerda, B. A.; Horn, D. M.; Cohen, J. S.; McLafferty, F. W.; Brown, H. A. Electrospray Ionization Mass Spectrometry Analysis of Changes in Phospholipids in Rbl-2h3 Mastocytoma Cells During Degranulation. Proc. Nat. Acad. Sci. U.S.A. 2001, 98, 7152-7157.

17. Berry, K. A. Z.; Murphy, R. C. Electrospray Ionization Tandem Mass Spectrometry of Glycerophosphoethanolamine Plasmalogen Phospholipids. J. Am. Soc. Mass Spectrom. 2004, 15, 1499-1508.

18. Harvey, D. J. Matrix-Assisted Laser-Desorption Ionization MassSpectrometry of Phospholipids. J. Mass Spectrom. 1995, 30, 1333-1346.

19. Marto, J. A.; White, F. M.; Seldomridge, S.; Marshall, A. G. Structural Characterization of Phospholipids by Matrix-Assisted Laser-Desorption Ionization Fourier-Transform Ion-Cyclotron Resonance Mass Spectrometry. Anal. Chem. 1995, 67, 3979-3984

20. Ayorinde, F. O.; Eribo, B. E.; Balan, K. V.; Johnson, J. H.; Wan, L. W Determination of Major Triacylglycerol Components of Polyunsaturated Specialty Oils Using Matrix-Assisted Laser Desorption Ionization Time-of-Fight Mass Spectrometry. Rapid Commun. Mass Spectrom. 1999, 13, 937-942.

21. Schiller, J.; Arnhold, J.; Benard, S.; Muller, M.; Reichl, S.; Arnold, K. Lipid Analysis by Matrix-Assisted Laser Desorption and Ionization Mass Spectrometry: A Methodological Approach. Anal. Biochem. 1999, 267, 46-56.

22. Benard, S.; Arnhold, J.; Lehnert, M.; Schiller, J.; Arnold, K. Experiments Towards Quantification of Saturated and Polyunsaturated Diacylglycerols by Matrix-Assisted Laser Desorption and Ionization Time-ofFlight Mass Spectrometry. Chem. Phys. Lipids 1999, 100, 115-125.

23. van den Brink, O. F.; Boon, J. J.; O'Connor, P. B.; Duursma, M. C.; Heeren, R. M. A. Matrix-Assisted Laser Desorption/Ionization Fourier Transform Mass Spectrometric Analysis of Oxygenated Triglycerides and Phosphatidylcholines in Egg Tempera Paint Dosimeters Used for Environmental Monitoring of Museum Display Conditions. I. Mass Spectrom. 2001, 36, 479-492.

24. Zabrouskov, V.; Al-Saad, K. A.; Siems, W. F.; Hill, H. H.; Knowles, N. R. Analysis of Plant Phosphatidylcholines by Matrix-Assisted Laser Desorption/Ionization Time-of-Flight Mass Spectrometry. Rapid Commun. Mass Spectrom. 2001, 15, 935-940.

25. Murphy, R. C.; Fiedler, J.; Hevko, J. Analysis of Nonvolatile Lipids by Mass Spectrometry. Chem. Rev. 2001, 101, 479-526.

26. Rujoi, M.; Estrada, R.; Yappert, M. C. In Situ MALDI-TOF MS Regional Analysis of Neutral Phospholipids in Lens Tissue. Anal. Chem. 2004, 76, 1657-1663.

27. Al-Saad, K. A.; Siems, W. F.; Hill, H. H.; Zabrouskov, V.; Knowles, N. R. Structural Analysis of Phosphatidylcholines by Post-Source Decay Matrix-Assisted Laser Desorption/Ionization Time-of-Flight Mass Spectrometry. J. Am. Soc. Mass Spectrom. 2003, 14, 373-382.

28. Song, Y.; Talaty, N.; Tao, W. A.; Pan, Z.; Cooks, R. G. Rapid Ambient Mass Spectrometric Profiling of Intact, Untreated Bacteria Using Desorption Electrospray Ionization. Chem. Commun. 2006, 61-63.

29. Wiseman, J. M.; Puolitaival, S. M.; Takats, Z.; Cooks, R. G.; Caprioli, R. Mass Spectrometric Profiling of Intact Biological Tissue by Using Desorption Electrospray Ionization. Angew. Chem. Int. Ed. 2005, 44 7094-7097.

30. Wiseman, J. M.; Ifa, D. R.; Song, Q.; Cooks, R. G. Tissue Imaging at Atmospheric Pressure Using Desorption Electrospray Ionization (DESI) Mass Spectrometry. Angew. Chem. Int. Ed. 2006, 45, 7188-7192.

31. Ifa, D. R.; Wiseman, J. M.; Song, Q. Y.; Cooks, R. G. Development of Capabilities for Imaging Mass Spectrometry under Ambient Conditions with Desorption Electrospray Ionization (DESI). Int. J. Mass Spectrom. 2007, 259, 8-15.

32. Costa, A. B. Cooks, R. G. Simulation of Atmospheric Transport and Droplet Thin-Film Collisions in Desorption Electrospray Ionization. Chem. Commun. 2007, 3915-3917.

33. Ifa, D. R.; Gumaelius, L.; Eberlin, L. S.; Manicke, N. E.; Cooks, R. G. Forensic Analysis of Inks by Imaging Desorption Electrospray Ionization (DESI) Mass Spectrometry. Analyst 2007, 132, 461-467. 
34. Cech, N. B.; Enke, C. G. Practical Implications of Some Recent Studies in Electrospray Ionization Fundamentals. Mass Spectrom. Rev. 2001, 20 , 362-387.

35. Ifa, D. R.; Manicke, N. E.; Rusine, A. L.; Cooks, R. G. Quantitative Analysis of Small Molecules by Desorption Electrospray Ionization Mass Spectrometry from Polytetrafluoroethylene Surfaces, Rapid Commun. Mass Spectrom. In press. doi:10.1002/rcm.3377.

36. Jensen, N. J.; Gross, M. L. A Comparison of Mass-Spectrometry Methods for Structural Determination and Analysis of Phospholipids. Mass Spectrom. Rev. 1988, 7, 41-69.

37. Hsu, F. F.; Bohrer, A.; Turk, J. Formation of Lithiated Adducts of Glycerophosphocholine Lipids Facilitates Their Identification by Electrospray Ionization Tandem Mass Spectrometry. J. Am. Soc. Mass Spectrom. 1998, 9, 516-526.

38. Larsen, A.; Uran, S.; Jacobsen, P. K.; Skotland, T. Collision-Induced Dissociation of Glycero Phospholipids Using Electrospray Ion-Trap Mass Spectrometry. Rapid Commun. Mass Spectrom. 2001, 15, 2393-2398.

39. Han, X. L.; Gross, R. W. Electrospray-Ionization Mass Spectroscopic Analysis of Human Erythrocyte Plasma-Membrane Phospholipids. Proc. Nat. Acad. Sci. U.S.A. 1994, 91, 10635-10639.

40. Hsu, F. F.; Turk, J. Electrospray Ionization/Tandem Quadrupole Mass Spectrometric Studies on Phosphatidylcholines: The Fragmentation Processes. J. Am. Soc. Mass Spectrom. 2003, 14, 352-363.

41. Ho, Y. P.; Huang, E. A Novel Structural Analysis of Glycerophosphocholines as TFA $/ \mathrm{K}(+)$ Adducts by Electrospray Ionization Ion Trap Tandem Mass Spectrometry. Rapid Commun. Mass Spectrom. 2002, 16, 1582-1589.

42. Hsu, F. F.; Turk, J. Charge-Driven Fragmentation Processes in Diacyl Glycerophosphatidic Acids Upon Low-Energy Collisional Activation. A Mechanistic Proposal. J. Am. Soc. Mass Spectrom. 2000, 11, 797-803.

43. Vernooij, E. A. A. M.; Brouwers, J. F. H. M.; Kettenes-van den Bosch, J. J.; Crommelin, D. J. A. RP-HPLC/ESI MS Determination of Acyl Chain Positions in Phospholipids. J. Sep. Sci. 2002, 25, 285-289.
44. Huang, Z.; Gage, D. A.; Sweeley, C. C. Characterization of Diacylglycerylphosphocholine Molecular Species by FAB-CAD-MS/MS: A General Method Not Sensitive to the Nature of the Fatty Acyl Groups. J. Am. Soc. Mass Spectrom. 1992, 3, 71-78.

45. Hvattum, E.; Hagelin, G.; Larsen, A. Study of Mechanisms Involved in the Collision-Induced Dissociation of Carboxylate Anions from Glycerophospholipids Using Negative Ion Electrospray Tandem Quadrupole Mass Spectrometry. Rapid Commun. Mass Spectrom. 1998, 12, 1405-1409.

46. Harrison, K. A.; Murphy, J. P. Negative Electrospray Ionization of Glycerophosphocholine Lipids: Formation of $[\mathrm{M}-15]^{-}$Ions Occurs Via Collisional Decomposition of Adduct Anions. J. Mass Spectrom. 1995, 30, 1772-1773.

47. Coetzee, T.; Fujita, N.; Dupree, J.; Shi, R.; Blight, A.; Suzuki, K.; Suzuki, K.; Popko, B. Myelination in the Absence of Galactocerebroside and Sulfatide: Normal Structure with Function and Regional Instability. Cell 1996, 86, 209-219.

48. Hsu, F. F.; Turk, J. Studies on Sulfatides by Quadrupole Ion Trap Mass Spectrometer with Electrospray Ionization: Structural Characterization and Fragmentation Processes That Include an Unusual Internal Galactose Residue Loss and the Classical Charge-Remote Fragmentation. J. Am. Soc. Mass Spectrom. 2004, 15, 536-546.

49. Chen, S. Tandem Mass Spectrometric Approach for Determining Structure of Molecular Species of Aminophospholipids. Lipids 1997, 32, 85-100.

50. Hsu, F. F.; Turk, J. Characterization of Phosphatidylinositol Phosphatidylinositol-4-Phosphate, and Phosphatidylinositol-4,5Bisphosphate by Electrospray Ionization Tandem Mass Spectrometry: A Mechanistic Study. J. Am. Soc. Mass Spectrom. 2000, 11, 986-999.

51. Hsu, F. F.; Turk, J. Structural Characterization of Cardiolipin by Tandem Quadrupole and Multiple Quadrupole Ion-Trap Mass Spectrometry with Electrospray Ionization. J. Am. Soc. Mass Spectrom. 2005, $16,491-504$. 